\section{No electrostatic sense in snakes}

SIR - Vonstille and Stille ${ }^{1}$ found that a disembodied rattlesnake rattle creates an electrostatic charge when vibrated, as does snake skin rubbed on the substrate, from which they conjectured that rattlesnake tongue-flicking (tongue scanning) is an electrostatic sense used to locate other rattlesnakes and, it is implied, prey as well. Although they stated that "it will be difficult to test the hypothesis", there is a wide literature refuting their conclusion.

Tongue-flicking and the presence of a rattle in snakes are neither logically nor phylogenetically associated. By far the vast majority of snakes lack rattles, but all snakes and lizards (including quadrupedal species that do not drag their skin on the substrate) exhibit tongue-flicking (both air-flicks and substrate-touches), a plesiomorphic feature of squamate reptiles ${ }^{2}$. Therefore, there is neither a phylogenetic nor necessary functional link between the ability to create an electrostatic charge, either by skin dragging or with a rattle, and the behaviour of tongue-flicking. In contrast, the role of tongue-flicking in stimulating the vomeronasal organs (a nasal chemical sense) is unequivocally established ${ }^{3-5}$ and is both necessary and sufficient to explain virtually all behaviours associated with tongue-flicking.

The fact that snake skin lacks "electrical discharge points in the form of hair, feathers, bristles, setae or spinules" is more logically related to the phylogenetic constraint of being a squamate reptile, as opposed to a mammal or a bird, than it is to adaptation for generating electrostatic charges. As Vonstille and Stille noted, generation of such an electrostatic charge with the skin is "in common with all other dry-skinned land animals".

Comparative data show convincingly that the rattlesnake rattle is an adaptation for defensive warning ${ }^{6}$, which contradicts Vonstille and Stille's conclusion. Defensive tail vibration in snakes clearly preceded the evolution of the rattle. Because a rattle enhances the performance of an ancestral behaviour, and functions in a defensive/warning capacity at the present time, it is robustly inferred to be an adaptation for this function?

Vonstille and Stille noted the distinction between air-flicks (tongue-scanning) and substrate-touches in snake tongueflicking behaviour and suggest that airflicks function for electrostatic sensation. However, despite their assertion that such air-flicks are a "long-standing puzzle", the distinction between air-flicks and substrate-touches has been clearly related to differences in volatility of the chemicals sensed $^{5,8-12}$, and therefore such behaviour 26 is once again related to vomeronasal stimulation.

The electrostatic sensory hypothesis ${ }^{1}$ requires that the slender prongs of snakes' forked tongues sense slight bending caused by attraction or repulsion of environmental charges. First, a chemosensory hypothesis for the evolution of forked tongues in snakes and other squamates is now overwhelmingly supported. Second, most squamates lack forked tongues but, nonetheless, frequently air-flick. Third, forked tongues have evolved independently up to four times, and the origin of the forked morphology is independent of both limblessness and tail rattles ${ }^{13}$. In other words, ancestral species were unable to generate electrostatic charges, but evolved the lingual behaviour and morphology said to be an adaptation for the perception of such charges. Fourth, histological and ultrastructural studies of snake tongues have failed to find the sensory organs required by the hypothesis for sensing tine displacement ${ }^{14,15}$.

Vonstille and Stille referred to a behavioural experiment they performed to test their hypothesis. Their brief description strongly suggests that results were random with respect to the snakes' ability to discern electrostatic charges.

We do not dispute the observation that snake skin and rattlesnake rattles produce electrostatic charges, nor that rattlesnakes often flick their forked tongues into the air. However, available data refute the notion of these as adaptations for the production and perception of electrostatic charges. Such electrostatic charges are likely to be epiphenomena arising from structures evolved for other purposes.

\section{Kurt Schwenk}

Department of Ecology

and Evolutionary Biology,

University of Connecticut,

Storrs, Connecticut 06269-3043,

USA

Harry W. Greene

Museum of Vertebrate Zoology and

Department of Integrative Biology,

University of California,

Berkeley,

California 94720-3160, USA

VONSTILLE AND STILLE REPLY - We agree with Schwenk and Greene that lizards and snakes use tongues to aid chemosensation - this combination is enhanced by the attraction of particles to the tongue in forms generating electrostatic charges. Snakes differ from nearly all dry skin animals in having no bristles, hair or other static discharge points; natural selection favours static charge production in snakes. A resting rattlesnake, when disturbed, begins flight, circular-in-place movement or rattling before tongue scanning begins - each behaviour produces electrostatic charges. Tail-rattling in ancestral snakes may have had selective advantages in con- serving energy and distracting attention away from vital body parts while generating charges. Thus ancestral snakes would have increased chemosensory and tongueflick acuity to identify and differentiate threats from shadows and neutral features to provide a clear functional link between tail rattling, electrostatic charges and snake tongue behaviour.

But in addition to lizard-like tongueflicks, snakes use tongue scanning. In arboreal and aquatic snakes, tongue scanning has no chemical function in the absence of chemical gradients typical of trails. We believe that snakes use tongue scanning to detect airborne electrons invading plumes of moisture marking cover. Moist air is electrically conductive and a space charge of electrons remains detectable until diluted by turbulence or lost due to other forces.

\section{W. T. Vonstille}

\section{W. T. Stille III}

Envi-Sci Center,

PO Box 5051.

Winter Park, Florida 32793, USA

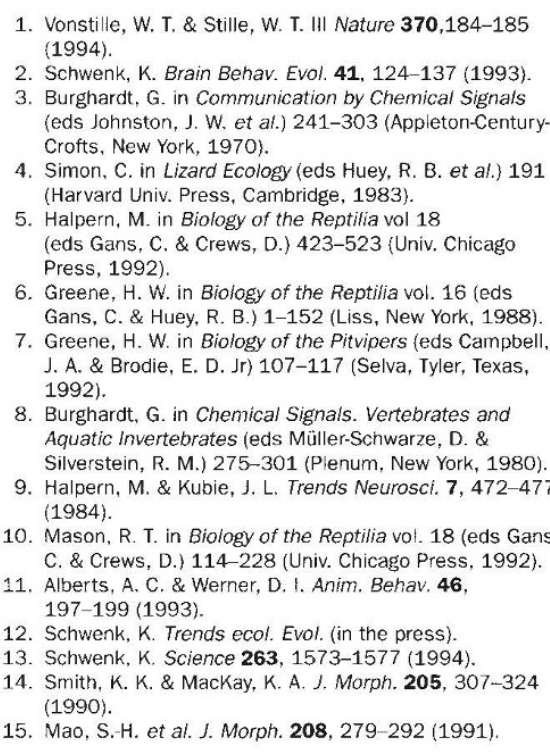

\section{Correction}

There was an error in the table of Scientific Correspondence by E. W. Thornton (Nature 372,$327 ;$ 1994). The left-hand column should increase in decades reading downwards. The table should read:

HEALTH COSTS OF PRIMARY ENERGY SOURCES

\begin{tabular}{cl}
$\begin{array}{c}\text { External health cost } \\
\text { adder (pence } \\
\text { per kWh) }\end{array}$ & $\begin{array}{c}\text { Source of primary } \\
\text { energy }\end{array}$ \\
$0.01-0.1$ & $\begin{array}{l}\text { Supply of electricity } \\
\text { by nuclear, solar, } \\
\text { wind, hydro or gas }\end{array}$ \\
$0.1-1$ & $\begin{array}{l}\text { Supply of electricity } \\
\text { by coal or oil }\end{array}$ \\
$1-10$ & $\begin{array}{l}\text { Energy conservation } \\
\text { by draught proofing } \\
\text { or double glazing }\end{array}$ \\
\hline
\end{tabular}

